\title{
The Poor in Democratic Society: A Pitfall in Social Poverty Aid Program
}

\author{
Rutiana Dwi Wahyunengseh ${ }^{1}$, Sri Hastjarjo ${ }^{1}$, Didik G. Suharto ${ }^{1}$, and Mahardhika M.A Pamungkas ${ }^{1}$ \\ ${ }^{l}$ Faculty of Social and Political Sciences, Universitas Sebelas Maret, Jl. Ir. Sutami 36 A, Surakarta, Indonesia \\ \{rutianadwi,sri.hastjarjo,didiksuharto\}@staff.uns.ac.id,mahardhikamap@student.uns.ac.id
}

Keywords: $\quad$ Active citizen, poverty, paradox, social accountability, democratic.

\begin{abstract}
The topic this paper is to question the paradox of active citizen representative's role in poverty coping policy process. This case study was conducted in one Indonesian city often becoming the location of fund distribution from international donor institution to reinforce civil society's role. The problems are: does active citizen actually contribute to the reinforcement of people capacity as the balancing power for government? Or instead does active citizen reinforce the patron-client relation, thereby becoming active clientelism? This article aims to address the paradox of active citizen from social accountability theory perspectives. The method employed is case study with an interpretative discourse analysis and interpretative phenomenon analysis. Interpretive inquiry is used to identify accountability pathology, i.e. the symptoms of comprehension biases towards targeted group and its implications on the public accountability substances. This research found the emergence of elitist pathology risk and information commodification in determining targeted group data. This research contributed prepositional finding of pathology pitfall in which poverty alleviation program instead of perpetuated poverty. This research recommended the publication of poverty indicators transparently to determine the targeted group and the utilization of it in integrated manner between Local Government Agencies as the determinant of poverty alleviation program. Further research was recommended to study the effect of poverty coping program acceptance on the group based on the relationship of targeted group and political actors and apparatuses.
\end{abstract}

\section{INTRODUCTION}

Poverty problem is a global threat. Alleviating any form of poverty is the first goal of Sustainable Development Goals. In the fifth year, in 2030, the target is to build poor people security (tenacity) in dealing with vulnerable situation and to reduce their vulnerable to extreme event such as extreme event related to climate, economic, social and environment shock also natural disaster.

The case occurring in Indonesia shows that data of "new poor people" happens any time. Therefore, the database operated so far and updated once in 3 years nationally, cannot capture new poor citizens when data recollection is conducted. National Government in this case, Poverty Coping National Team (TNP2K) develops Independent Updating Mechanism of Poor and Destitute Management Program Integrated Data. The role of government is required to collect the data of new poor people and the change of poverty indicator from the registered poor people to find out the change of poverty rate. Government Regulation No.63 of 2013 about Areabased Poor and Destitute Management mentions that the attempt of coping poverty should have deadline, that is, when the poverty aid intervention recipient group is capable of continuing their reasonable life. However, the case in Indonesia shows that Poverty Alleviation as if becomes an everlasting phenomenon, remaining to be existing along the time thereby always becoming the material of campaign for all local leader candidates. Metadata resulting from the research on poverty in Indonesia shows that the challenges encountered in managing the poverty coping program are: (1) not targetappropriate due to less accurate data; (2) not program-appropriate due to the weak information on the society's need; (3) inappropriate aid distribution schedule; (4) quality of aid not as expected; and (5) disorganized management and distribution of social aid. All policies issued by Indonesian government are supply driven for the attempt of alleviating 
poverty. Furthermore, the question from demand driven is how is the poor people's response to various poverty alleviation aids?

Previous studies focus on the evaluation on the factors causing the failure of poverty coping program implementation in local area. This study will complement the finding of previous studies by explaining that there is an unrevealed pathological symptom behind the result of evaluation on the factor causing the failure of poverty coping policy. Particularly, this study addresses the contribution of society to perpetuating the society's poverty status.

The analysis is conducted using public accountability theory. The novelty of current study lies on the use of social accountability pathology discoursing as the analysis instrument. Social accountability pathology is defined as the symptoms resulting in social accountability dysfunction. Social accountability normatively reinforces democratic values such as justice, access equality, anticorruption, and the similar, for example unfair budget allocation, domination of majority group, patronage, clientelism, corruption, and the similar.

Considering the empirical condition, this study aims to explain the pitfalls in social poverty aid program. The pitfall intended is the factors affecting biased determination of "who the poor is". The determination of poverty status is the entrance for the deviation of poverty coping program aid benefit. The determination of "who is entitled to receive poverty aid" affects the successful achievement of poverty coping program. In this case, active citizen has an important role for monitoring and stating aspiration among the poor to government.

\section{METHODS}

\subsection{Social Accountability Theory}

The social accountability theory intended in this study is the use of social accountability substance framework. Public accountability concept in democratic governance is defined as converging the active civil citizens and the responsive government (Mulgan , 2003; Kabeer, 2005; Erkkila, 2007; Klein, Kiranda, Bafaki, Okiror, Kamp, 2011; Schillemans, 2013). Social accountability concept is the development of public accountability variants. Social accountability is public accountability in hybrid form, that is, working in the existing formal accountability system and reinforcing the horizontal accountability system to make the vertical accountability effective (Goetz and Jenkins, 2001).
Social accountability is called society driven horizontal accountability as well to get direct answer from government and people representatives in parliament as the formal accountability holder (Stapenhurst, and O'Brien, 2009; Adesopo, 2011). In addition, it is also called informal institutions of accountability, in which the society's initiative to ask for accountability is actually is not supported by legal formal authority ownership as the accountee (Tsai, 2007). Social accountability mechanism can be initiated by civil society or along with government and other actors (Ackerman, 2003; Clarke and Missingham, 2009).

Social accountability is the relation between citizens who have right to ask for and to receive accountability (as accountee) of government and politicians as the public resource organizer that should be accountable for (as the accountor) (Novak, 2007; Niraja, 2008; Camargo and Jacobs, 2013). The relation between accountor and accountee occurs in both institutional and local social-cultural structures.

Accountor-accountee relation analysis is used in this research to explain the problem of relation between accountor and accountee, dynamic information asymmetry, and incentive link triggering the actor's behaviour in social accountability space. Basic assumption used concerning the problem in the relation between accountor and accountee is self-interest, information asymmetry or information transparency, and opportunistic behavior (McGee and Peruzzotti and Smulovitz , 2006; Bjorkman, 2009; Greiling and Spraul, 2010; Goetz \& Gaventa, 2010; ANZA-EAP, 2012; Merritt, 2013; Fox, 2015).

Wahyunengseh's (2016) study explained the symptoms (phenomena) resulting in social accountability mechanism dysfunction or a condition disrupting the functioning of social accountability substantively. Social accountability dysfunction is counterproductive to democratic values. This phenomenon is called social accountability pathology. The pathology impacts on the social accountability system remaining to run procedurally, but substantive dysfunction occurs, for example when there is budget allocation injustice, majority group domination, patronage, clientelism, and corruption. This study analyzes the phenomenon of actor behaviour and its point of view in the social accountability mechanism practice of local poverty coping program.

This research employed collective case study type with interpretive perspective, analysing the actor's behaviour phenomenon and its point of view 
on the social accountability practice of local poverty coping program. In addition to interview and to use FGD, this study employed content analysis technique as well. Content analysis was conducted on SPKD (Local Poverty Coping Strategy) and Renja (Work Plan) documents of Local Government related to poverty alleviation program.

\subsection{Data Collecting}

Surakarta City as the research location has strong Javanese cultural background having values different from democratic theoretical values becoming the primary foundation of civil society movement. Nevertheless, Surakarta City belongs to "medium city" with varying types of society organizations and becoming the targeted group of international donor institution. This study combines local cultural environment context and international value intervention as the variable to study the relation of active citizen to bureaucracy and other citizen groups. The result identifies the characteristic tendency of active citizen to be between democratic phenomena of active citizen or active clientilist

The informant of research consisted of 38 informant from government group and Local Poverty Coping Coordination Team (TKPKD) (G), 25 from active citizen group (AC), and 56 from society group (S). The case group serving as the object of research included: (i) public participation in the process of determining the poverty aid recipient group, (ii) society's attitude to local poverty aid; (iii) characteristics of the relation between poverty aid recipient and government. The triangulation technique used in this study included research informant triangulation, by asking the same question subject to different informants, and data collection method triangulation, in which the topic was explored in three ways: in-depth interview, field observation, and document analysis.

\section{RESULT AND DISCUSSION}

Considering the findings of previous studies, this current study suggests that active citizen represents citizen ability, either individually or in group, to fight for three issue domains: (a) people participation control the government in collective action; (b) encouraging right-based development, include poverty alleviation; (c) involving people in political process to result in an democratic government (Peter P. Houtzager \& Arnab K. Acharya). Active citizen is believed as improving the quality of social accountability in public budgeting, thereby can suppress the risk of deviating public budget use for elite capture, reduce corruption rate, reduce authority abuse, and improves public sector quality. Active citizen are expected to strengthen the pro poor budget. (Ackerman, 2005; ANZA-EAP, 2012; Cornwal, 2008; Mulgan, 2008; Yang and Callahan, 2005; Davies, 2012).

Normatively, in democratic governance, a basic assumption on democracy is closely related to power sharing, the balanced power between state and civil society participation. Therefore active citizen is represented as the primary key to sustainable development in participative manner, because they can build bargaining power with government and other public agent involved in community issue in decision making process in the area in which they are affected (Malena, et.al., 2004; Fung, 2006). However, in practice, the tendency of public participation tends to be biased politically to the group owning excessive power, including those with high income and high education. Governance builds civil capacity to improve their interest in participating in the governance. At the same time, either intentionally or unintentionally, citizens' subjugation ethos or pride can be cultivated since they are involved in power, so the clientelism ethos occurs (Peter, 2009; Cox, 2009, Hong, 2015).

Based on reference that is stated above, this study focuses its analysis on the role of active citizens in improving democratic governance of local development, particularly the local poverty management program. The theory used is social accountability theories. Active citizen analysis is aimed at several areas: its inception process, its activity participation area, its relation to government, its relation to other society group and its accountability objective orientation.

Data of Social Service shows that about $20 \%$ of poverty aid recipients, when validated in their individual house addresses, do not fulfil the requirement of poverty indicator. Data triangulation on surrounding people (B and $\mathrm{AC}$ ) explains that when data collection of poor group shows that there is some individual group considers it as the opportunity of taking profit. As a result, the nonpoor group having access to data collection officer benefit from the opportunity. It shows that the manifestation of preposition "poverty aid gives incentive to reinforce poverty when it is not compensated with sanction mechanism or accountability demand". Interview with active citizen (AC) informant shows that: "we have had SIK team, just like the government's instruction. 
Indeed some invalid data are still found but when the invalid family name has relation to those having influence it will remain to be in the poor data, while they are actually not poor". From the explanation above, the result of research indicates that opportunism also befalls society, to maintain harmony with the ruler.

Related in aid poverty program, document analysis on the evaluation of performance of work tool aid recipient shows that $47 \%$ of them remain to continue their business in the last 1 year since getting training and work tool aid. Data triangulation on the interview with government (LA), Activist (AC) and beneficiary (B) explains: "Some of them have never embarked on their business, and they resell the tool as soon as the training has been completed. They usually do so because they indeed have never operated a business and some others often get the aid as they are designated by irresponsible apparatus or those having connection to political actors". It indicates the manifestation of preposition: "Poverty aid gives incentive to strengthen poverty when it is not compensated with sanction mechanism or accountability demand".

Interview with poverty aid beneficiary (B) and FGD with active citizen (AC) finds data showing that $40 \%$ of respondents access the aid because they know familiarly the political party cadre; $40 \%$ s know the government apparatus; 20\% get information from Neighborhood (thereafter called Rukun Tetangga $(R T)$ ) meeting, and from fellow citizen. Some informants (B) told similarly about the source of aid access: "I got all poverty aid cards, nearly all citizens in our complex got them, because we have strong representatives in DPRD (Local Legislative Assembly)." It shows the manifestation of preposition: "The utilization of data and poverty information for poverty social aid allocation potentially strengthens (reinforces) the patron-client relation".

Poverty is inseparable from the concept of interdependent culture and the wish to be served. The implication is that the poverty coping program should touch the cultural domain and the perspective in order to have the disinclined feeling for being dependent on giving. The explanation of an informant not willing to be published reveals the tendency of deviating behaviour emerging as the excess of poverty coping program. Firstly, it generates the character of willingness to pretend to be poor people in order to utilize government policy. Nevertheless, their neighbour does not want to report the fraud as long as it does not harm their interest. It can be seen from the following case:
"The admission of poor student in favourite public school is harmful to those not poor and having high achievement. Only due to SKTM (Recommendation for Poor People) the students with low score can be admitted. Meanwhile, they are actually not poor, but the lurah (village head) cannot refuse their application for SKTM. But finally, it can be detected when their neighbour whose children were replaced for their rank reports it to the school".

In conclusion, poverty is considered as commodity, even by active citizen. It is the commodity often exchanged with the political power holder using political support, particularly those having relation to political actor. Social accountability concept emphasizing the role of active citizen to reinforce political accountability assumes that society group acts on, thereby can prevent the public resource stealing for elite group. It is this paradox of civil society that potentially results in paradox of active citizen-clientelism.

The paradoxical phenomenon of active citizen and clientelism can be found in public consultation forum to cope with local poverty in participative way. The principal-agent relation potentially creates moral hazard and opportunistic behaviour constituting normative deviation. Moral hazard is the problem occurring when the agent does not implement what has been agreed with its principal (normative). Opportunistic behaviour is to utilize resource and access owned for personal or selfinterest. Citizen Representatives can also be the agent when they represent other citizen group. Public consultation of poverty aid program in research location indicates this opportunistic behaviour phenomenon. From society aspect, it can be found from the pride for being involved in government's power circle. In the context of local culture, government is the ruling group, so that being close to government means to increase prestige and access to benefit. On the other hand, due to the pride of being the part of power, the representatives of active citizen voice the opinion differently from government's agenda reluctantly. In the forum, there is no dialog process to address the rationality behind decision making. Citizen forum is directed to the attempt of building consensus between government agenda and active citizen representatives in the co-opted forum nuance.

Behind the active citizen forum, some matters are found characterizing the opportunism phenomenon among civil citizen flourishing the clientelism growth. The active citizens' subjection shifts from the idealism of reinforcing citizen autonomy to reinforcing self-existence by 
embedding them into the power (money or social position) holder. Field informant states that there is a shift of profession from sellers to meeting activist. The more the NGOs conducting facilitation to reinforce the citizen forum, the higher is the amount of money incentive received. It grows the civil citizen's dependence and clientelism to those often paying them for their participation in citizen forum.

Normatively, active citizen is believed to grow the citizens' awareness and to improve bargaining power in the attempt of fighting for their fate. However, on the other hand, the citizen forum elite tend to be entrapped in conducting forum commodification. It means that active citizens are aware of having the movable mass, so that they have bargaining power before the government. In this case, society forum potentially becomes an instrument of suppressing the ruler or bartering interest. Such mindset leads to the emergence of policy broker or black market transaction, and tends to reinforce the clientelism of power holder. For example, in the case of public consultation in Street Vendor arrangement process in Surakarta City, a phenomenon emerges in which the leader of forum group tends to get more facility from government in the form of more strategic location more kiosk than other participative members, or get additional project from government.

The result of current study also identifies the presence of active citizen group serving as the peace intermediary, when there is a case between certain citizen group and government. Information from government and active citizens in Surakarta shows that there is an active citizen group used by government to suppress other active citizen group in order not to endanger the stability of government policy. There are some modes used including active citizens becoming the ruler's clientelism that offers the solution to solve the problem in isolation room between them so that there is no transparency to the public.

The general pattern withdrawn from Surakarta City shows that active citizens tend to be co-opted in the power circle solidifying the clientelism patronage relation. It shows democratic paradox, in which participative mechanism that should reinforce autonomy and independency of active citizens to control power, instead perpetuates the power domination relation

\section{CONCLUSIONS}

This study finds some preposition. Firstly, poverty Coping Policy is affected by individual ability, social and cultural environment, and local political policy. The same treatment of poverty coping policy intervention results in different changes in different group.

Secondly, poverty aid gives incentive to strengthen poverty when it is not compensated with sanction mechanism and accountability demand. In the group having character to take shortcut and inadequate spirit of independency, poverty aid will reinforce the culture of being dependent to governments' giving.

Thirdly, the utilization of poverty data and information for allocating poverty social aid potentially strengthens the patron-client relation. The groups close to political actor tends to have more access to poverty coping program aid.

Fourthly, the implementation of poverty coping policy results in some social accountability pathology. Pathological phenomenon leading to a biased utilization of poverty coping program results from both government and public domains. From government domain, it is triggered by procedural formalistic culture triggering the emergence of: (i) bureaucratic opportunism pathology, (ii) buckpassing pathological symptom, (iii) Atrophy of Personal Responsibility, and (iv) Budget using elite captures pathological symptoms. From public domain, it is triggered with commodification culture triggering the emergence of: (i) commodification of poverty data, (ii) patronage, clientelism, favoritism phenomenon, and (iii) public need commodification pathological symptom.

This study finds that bureaucratic cultural environment impacts on the quality of active citizen forum. When bureaucratic culture environment contains collusion and nepotism defects, active citizen forum will be defect with cooptation and forum commodification, solidifying patron-client relation, resulting pseudo active citizen forum.

Practical recommendation given to the implementation of poverty coping policy is as follows. Firstly, data of poverty should be discussed in the smallest environment from which the data is organized. Secondly, indicator of poverty and requirement of target group feasibility should be published up to the lowest society lowest level through varying media. Thirdly, community-based monitoring system should function actively to report deviation and bias occurring in the term of poverty coping intervention. 
Recommendation given for further research is based on preposition that cultural and structural factors serve as the important element determining the successful inclusive poverty coping strategy that is not temporary but permanent and sustainable. This research recommends further research to be conducted on the effect of poverty coping program acceptance on the group having close relation to political party cadre and the beneficiary group having no relation to political party. This research is expected to give information about the extent to which the preposition formulated in this research, "the utilization of poverty data and information for allocating poverty social aid potentially strengthens the patron-client relation" is actualized

\section{REFERENCES}

Ackerman, J.M, 2005, Social Accountability in the Public Sector: A Conceptual Discussion, Social Development Paper 82, March, Washington DC.

ANSA-EAP, 2012, Social Accountability Perspectives and Practices in East Asia and the Pacific, Social Accountability Stocktaking Report- Indonesia, Manila, Affiliated Network for Social Accountability in East Asia and the Pacific (ANSA-EAP), http://www.ansa-eap.net/assets/784/ANSAEAP_Stocktaking_Report.pdf.

Brinkerhoff, D.W and Wetterberg, A., 2015, Gauging the Effects of Social Accountability on Services, Governance, and Citizen Empowerment, Public Administration Review, doi: 10.1111/puar.12399, www.onlinelibrary.wiley.com

Cox, J. (2009). Active citizenship or passive clientelism? Accountability and development in Solomon Islands. Development in Practice, 19:8, 964-980.

Dalton, R. J. (2006). Citizen politics: Public opinion and political parties in advanced industrial democracies (4th ed.). Washington: Congressional Quarterly Press

Davies, A, Simon, J, 2012, The value and role of citizen engagement in social innovation. A deliverable of the project: "The theoretical, empirical and policy foundations for building social innovation in Europe" (TEPSIE), European Commission - 7th Framework Programme, Brussels: European Commission, DG Research

Fox, A.J, 2015, Social Accountability: What Does the Evidence Really Say?, World Development Vol. 72, pp. 346-361.

Fung, A, 2003, Survey Article: Recipes for Public Spheres: Eight Institutional Design Choices and Their Consequences, The Journal of Political Philosophy 11(3), pp. 338-367.

Goetz, E.G, 2003. Clearing the Way: Deconcentrating the Poor. Washington DC: Urban Institute Press.
Goering, J, Jeins, J.D, \& Richardson,T,M. 2003, "What have we learned about housing mobility and poverty deconcentrration" in J. Goering, \& J. D. Feins (eds), CHoosing a better life? Evaluating the moving to opportunity social experiment (pp. 3-36). Washington DC: Urban Institute Press, 2003

Greiling, D. and Spraul, K., 2010, Accountability and the Challenges Information Disclosure, Public Administration Quarterly, Vol. 34, No. 3 (Fall), pp. 338-377

Hong, S., 2015. Citizen Participation in Budgeting: A Tradeoff Between Knowledge and Inclusiveness. Public Administration Review, forthcoming

Malena, C., Forster, R., Singh, J., 2004. Social Accountability: An Introduction to Concept and Emerging Practice. Social Development Papers, Participation and Public Engagement, Paper No. 76 December 2004.

Maskovsky, J. 2001,"Afterword: Beyond the privatist consensus" in J. Goode, \& J. Maskovsky (eds), The new poverty studies. New York: New York University Press, 2001.

Mulgan, R, 2000, Accountability: An Ever Expanding Concept?, Public Administration, 78: 555, www.onlinelibrary.wiley.com

Peter P. Houtzager \& Arnab K. Acharya, 2010, Associations, active citizenship, and the quality of democracy in Brazil and Mexico

Peruzzotti, Enrique and C. Smulovitz, 2006, Enforcing the Rule of Law: Social Accountability in New Latin American Democracies, Pittsburgh: University of Pittsburgh Press

Wahyunengsih, Rutiana Dwi, 2016, Patologi Akuntabilitas Sosial (Studi Kasus dalam proses Perencanaan Penganggaran Daerah di Kota Surakarta dan Kota Magelang). PhD thesis, Yogyakarta: Universitas Gadjah Mada

Yang, K. and K. Callahan, 2007, Citizen Involvement Efforts and Bureaucratic Responsiveness: Participatory Values, Stakeholder Pressures, and Administrative Practicality, Public Administration Review, Vol. 67, No. 2 (March- April), pp. 249-264. 